The language and non-language benefits of literature in foreign language education: An exploratory study of learners' views

\title{
Art Tsang
}

The Chinese University of Hong Kong

Amos Paran

UCL Institute of Education, UK

\section{Wilfred W.F. Lau}

The Chinese University of Hong Kong

This document is an author deposited version. You are advised to consult the publisher's version if you wish to cite it.

Published version available at https://doi.org/10.1177/1362168820972345 


\title{
The language and non-language benefits of literature in foreign language education: An exploratory study of learners' views
}

\begin{abstract}
Set against the backcloth of increasing recognition and attention to literature in foreign language education (FLE) globally, this article reports part of a large-scale study of 1190 secondary-level learners' views of the benefits of literature, as instantiated by short stories (ShS) and poems and songs (PS) in their English-as-a-foreign-language learning. An inventory of 27 items (13 language-related and 14 non-language-related) was compiled with reference to previous studies and curricular documents. The analyses compared the two modules through independent t-tests, as well as including an exploratory factor analysis to examine latent factors. Findings reveal a three factor structure and a slightly positive view of the benefits of literature. ShS were perceived to be generally more beneficial than PS, especially in the domains of generic skills and work/studies. There were benefits common to ShS and PS, which by extension, may be universal to literary texts at large. This study makes a theoretical contribution by unveiling the potential value of literature in FLE and the three underlying factors of its perceived benefits. Practically, the inventory can be used by FL teachers to measure students' perceptions to inform their use of literature in FLE.
\end{abstract}

\section{Keywords}

Literature; Foreign Language Education; learners' perceptions; perceived benefits; stories; poems and songs 


\section{Introduction and Context}

Although different accounts exist of the role of literature in foreign language education (henceforth FLE) in the last 40 years (see, for example, the contrasting accounts in Bobkina \& Dominguez, 2014; Carter, 2007; Paran, 2006), it continues to be an important part of different FLE educational systems (see for example Bloemert, Jansen \& van de Grift 2016; Duncan \& Paran, 2018), and in many contexts it is tested as part of the school leaving exams (see Bloemert, Paran, Jansen \& van de Grift 2019; Paran, Spöttl, Ratheiser, \& Eberharter, 2021). This continuing presence of literature in FLE has also been accompanied by a rise in empirical research in this area. Recent research includes classroom observation studies (Duncan \& Paran, 2017, 2018; Wolthuis, Bloemert, Tammenga-Helmantel \& Paran, 2019; Cheung \& Hennebry-Leung 2020), action research (Nguyen, 2016), classroom interventions implementing specific instructional approaches (Nguyen, Janssen, Rijlaarsdam \& Admiraal 2016; Viana \& Zyngier, 2019), questionnaires to teachers (Duncan \& Paran, 2017, 2018), and curricular research (Kirchhoff, 2016; Luukka, 2017). A number of edited collections have appeared (e.g. Teranishi, Saito, \& Wales 2015; Bland 2018; Jones 2020), and a research network has been established - the Literature in Language Learning and Teaching Research Network of International Association of Applied Linguistics (AILA LiLLT REN, https://lilltresearch.net ). Importantly, some of the research appearing is beginning to focus on secondary education, although considering that most FLE takes place in the state school sector (Ur 2020), there is less research in this educational context than would be expected. In this paper, we focus on this sector, drawing on data from a large-scale study of the way literature plays out in FLE in secondary education in Hong Kong. We focus on one aspect of the wider research arena, namely, the views of learners regarding the benefits that accrue from using literature in FLE.

Learners' views are especially important since they can influence their approaches to learning (Struyven, Dochy, \& Janssens, 2005) and are significantly related to their academic performance (Williams \& Burden, 1997). Although students' views are unlikely to ever be unanimous, $\mathrm{Ng}(2004, \mathrm{p} .80)$ points out that their general views as "a collective phenomenon...can be mobilized on some particular issue and directed towards some kind of action" (e.g. curricular reforms and fine-tuned pedagogical approaches bringing about greater benefits to learners' needs, interests, and overall learning), thereby generating implications for stakeholders in education, such as curriculum developers, material designers, and teachers.

Hong Kong provides a suitable platform for research into literature in FLE because of the way in which literary texts are incorporated into the curriculum. The current senior secondary English-as-a-foreign-language (EFL) curriculum in Hong 
Kong was first introduced in 2009 and updated in 2014 (Curriculum Development Council \& Hong Kong Examinations and Assessment Authority [henceforth CDC \& HKEAA], 2014). It includes eight elective modules, classified into four language arts modules and four non-language arts modules, serving the purposes of "adding variety to the English Language curriculum, broadening students' learning experience and catering for their diverse needs and interests" (CDC \& HKEAA, 2014, p.29). The language arts modules highlight authentic materials of different styles, registers and genres, students' emotional experiences and personal responses, promotion of students' oral and writing skills, and development of students' attitudes (Carless \& Harfitt, 2013), thus drawing on a combination of Carter and Long's (1991) Language Model and Personal Growth Model. Each secondary school must offer at least one of the four elective literature-related (i.e. language arts) modules, namely Learning English through: Drama, Poems and Songs, Popular Culture, and Short Stories. Although in theory learners can choose the modules they take, in practice it is the schools rather than students who make the choice. For example, in a small scale study of the implementation of the language arts modules in one school in Hong Kong, Carless and Harfitt (2013) show how teachers chose the Short Stories module because they felt that the Poems and Songs and Drama modules required more literary expertise. Importantly, at present, the language arts modules are formally included in the Hong Kong Diploma of Secondary Education English Examination.

An important issue in studies of literature in the FL classroom is defining literature, which is far from straightforward (Gilroy \& Parkinson, 1996; Hall 2016). This complexity is compounded by the differences between educational systems and their approach to literature, to the study of literature, and to what is presented as literature to the learners. In the Hong Kong context, this is further complicated by the fact that teachers have the discretion to choose which texts they use in these modules, as well as the approach they use in their teaching, leading to a fairly wide variety of texts and approaches. From informal conversations with in-service teachers and our knowledge of the context, some teachers may not be using literary texts at all in the Drama and Popular Culture modules (for instance, in Drama, students may only be asked to read aloud scripts of everyday dialogues). We therefore focused on the two other genres, namely Short Stories (henceforth ShS) and Poems and Songs (henceforth PS). It is important to note that most ShS and PS materials designed or chosen are often non-canonical and in simple English (see examples of ShS and PS materials in the links in the appendices). It is also noteworthy that in this largely non-canonical selection of texts, poems and songs are essentially identical apart from the fact that songs have been set to music and poems have not. Therefore, lyrics can be viewed as a song when sung, and as a poem when read. 
This study examined the views of Hong Kong EFL learners of the genres that they were being exposed to in the language arts modules. The next section therefore focuses on previous studies which examined learners' views of literature in FLE.

\section{Learners' views of literature in FLE}

\section{Tertiary-level students' views}

Questionnaire studies that focused on learners' views of literature in FLE have reported mixed findings. Martin and Laurie (1993), in a small-scale $(n=45)$ study of French-as-a-foreign-language learners' views of literary and cultural content in FLE in Australia, found that the participants did not rate literature very highly except in reading, and generally thought that it played a relatively unimportant role in developing their linguistic competence. Davis et al. (1992) carried out a similar study on a larger scale $(n=175)$ with French and Spanish as a FL in the USA. However, the findings were quite different. They found that the participants had very positive attitudes towards literature - most students found the study of FL literature "personally rewarding" and thought that "majors and minors should be encouraged to take literature courses in the FL department" (p. 322). One of the largest relevant studies to date is Harlow and Muyskens (1994), in which 1373 students from twelve universities in the USA taking French or Spanish as a FL took part. Reading literature was ranked eleventh out of 14 in FLE priorities. Superficially, this seems rather negative, but a closer scrutiny of the mean scores reveals that most students actually thought that literature was important (mean score $=3.61 / 5 ; 5$ being extremely important) although their opinions were quite varied $(S D=1.08)$.

While these three studies investigated learners' general perception towards literature in FLE, other studies examined learners' attitudes in more specific contexts. Hirvela (2005) investigated 195 students' views towards the use of literature in composition lessons. More than half of the students (59.49\%) were positive about this, but a sizable group (35.9\%) provided negative responses. Similarly, Kuze (2015) conducted a study with four compulsory composition classes at a private university in Tokyo. The students read a number of short stories and completed writing tasks and a questionnaire. Kuze (2015) found that most participants were quite positive towards the use of literature in FLE. Approximately $85 \%$ of them had at least a slightly positive attitude towards literature-based writing and thought that this was effective in improving their English reading and writing skills to some extent.

As regards reading, Diaz-Santos (2000) researched learners' views of the use of techno-thrillers in English for science and technology classes. The participants thought that the lessons were informative and interesting and that the content was valuable. Yang (2002) investigated the use of science fiction. The learners were 
generally positive towards this genre. The perceived benefits which learners cited encompassed both linguistic and non-linguistic benefits, including greater confidence, self-perceived improvement in general reading and writing, greater eagerness to discuss, promotion of critical and logical thinking, and development of creativity and imagination. Liaw (2001) examined learners' perspectives on the use of five American short stories and also recorded positive feedback from the participants. Apart from gains in areas such as reflective thinking skills and confidence, the majority stated their preference for short stories over language textbooks and referred to their enjoyment when reading these short stories.

Overall, then, tertiary-level learners, in both general and specific FLE contexts, tend to be quite positive about different facets of (the use of) literature in the FL classroom.

\section{Secondary-level students'views}

Although secondary education is the locus of the majority of FLE, only a very small number of studies to date have investigated learners' views of literature in FLE in secondary settings. One early study, Akyel and Yalçin (1990), examined responses from 150 learners in five secondary schools in Turkey. The learners perceived novels as the most effective literary genre in developing their linguistic skills and cultural awareness; short stories and poetry were generally perceived as not instrumental to the development of their language skills. In particular, short stories, in students' views, were generally "boring, unrelated to their interests and generally unsatisfying" ( $p$. 176). In terms of contribution to developing language skills, learners viewed poetry as contributing least to their learning.

Schmidt (forthcoming) investigated learners' views of studying Shakespeare's works in Germany, collecting data from 417 students in 28 different courses in secondary schools in Bavaria. The respondents generally accepted Shakespeare as teaching content and thought it was relevant for them. Even though the learners expressed their concern about the linguistic difficulty of these texts, $80 \%$ of them completely accepted Shakespearean works being made compulsory in class.

More recently, Bloemert, Paran, Jansen and van de Grift (2019) carried out a survey in which 635 secondary school students from 28 classes in 15 different schools in the Netherlands responded to one single open question: "What do you think are the benefits of EFL literature lessons?" (p. 375). The majority of the respondents stated the benefits from a linguistic perspective such as vocabulary; around half mentioned gains relating to contextual aspects such as "learn(ing) about how people thought in different periods" (p. 379); one third touched upon the advantages from a reader's perspective such as "critical thinking skills and personal development" (p. 379); 
finally, only $12 \%$ of the learners stated benefits that were classified by Bloemert, Paran, Jansen and van de Grift (2019) as the 'Text approach', such as knowledge of literary terminology, or literary text types.

\section{Summary of learners'views}

To summarize, apart from some studies which presented rather general findings such as positive/negative attitudes towards literature and the importance/unimportance of literature, the benefits perceived by learners can be classified into language-related (e.g. improving reading and writing skills in Kuze (2015) and Yang (2002)) and non-language-related (e.g. cultural awareness in Akyel and Yalçin (1990); critical and logical thinking in Yang (2002)). This is in congruence with the case for literature in FLE in that in addition to enhancing language proficiency, literature also facilitates multiple aspects in learners' whole-person development. As Hall (2016, p. 464) points out, many of the syllabuses dealing with literature in FLE which are now appearing include aims that go beyond language teaching but are conceptualized as 'part of wider educational aspirations for ethical citizenship and (inter-)cultural awareness' (see also Heilbronn, 2019; Paran, 2008; Sivasubramaniam, 2006).

\section{Research gaps and motivation for the study}

The present study and the approach we took were propelled by a number of motives. First, as scholars such as Carter (2007) Hall (2015) and Paran (2008) have pointed out, in spite of the continuing presence of literature in FLE, literature in teaching and learning FLs has for many years been an under-researched area (though as we have indicated in our introduction, the past 5 years, and even more so the past 2-3 years, have been particularly productive). Related to this is our second motive: Studies on learners' views are especially research-worthy as their views play an influential role in their achievements (Williams \& Burden, 1997; see also Bloemert, Jansen, \& Paran, 2019). Also, students' and teachers' disparate expectations in FLE may cause disillusionment (Brown, 2009). The substantial number of studies of learners' attitudes towards different aspects of language education suggests the importance of extending similar investigations into literature in FLE (see also Bobkina \& Dominguez, 2014; Paran, 2008). Third, most of the pertinent studies were conducted at the tertiary level and much more research is needed at the secondary level, as secondary schools are where most FLE takes place across the globe (Paran, 2008; Ur, 2020). In addition, many tertiary-level participants in studies that investigate literature in FLE are likely already intrinsically interested in or at least motivated to study the language and its literature. For instance, Davis et al. (1992) point out that their participants were undergraduates who had enrolled in French and Spanish literature 
courses in a US university. Such studies present the views of only a very specific and limited group of learners, resulting in possibly a skewed view of more general attitudes.

As we have pointed out above, the definition of 'literature' is a contentious one; in addition, many studies use the term loosely, without defining for the learners what the term actually denotes (although in some cases this may be defined for the learners by the educational system within which their FLE is taking place). With different definitions in mind, the interpretation of the findings is not always straightforward. For instance, Harlow and Muyskens (1994) listed different areas in language that respondents had to rank from not very important to extremely important; the item relevant to literature was "Literature (read and understand poems, short stories, plays, novels, etc.)", thus providing a definition for the respondents. This is perhaps already more detailed than studies stating the term literature or similar terms such as literary texts without any elaboration (e.g. Bloemert, Paran, Jansen, \& van de Grift 2019; Martin \& Laurie, 1993). However, respondents may have different perceptions towards different literary genres; we know, for example, that attitudes to poetry are often very different from attitudes to other genres (Duncan and Paran, 2017). In this study, we therefore focused on two specific genres - short stories, and poems and songs - because of their relatively common occurrence in FL classrooms in general. Because a number of previous studies had found different attitudes towards different genres both by learners (Akyel \& Yalçin 1990) and by teachers (Duncan and Paran, 2017), we looked at the differences between views of the two genres for a more nuanced understanding of whether different literary genres are perceived similarly or differently. Likewise, a more systematic approach is needed in examining learners' perceptions. As shown above, some previous studies investigated only learners' general perceptions (e.g. overall perceived importance). Our investigation sought to to establish a more nuanced understanding of how literature is perceived to be beneficial to learners in different specific facets within the broad categories of language-related and non-language-related benefits. We thus sought to contribute to the field through conducting a study that would capture the views of a large number of learners in an underresearched sector (secondary state education), in a geographical context where such information is lacking (Hong Kong).

\section{Research Questions}

The part of the study reported here aimed at addressing three research questions:

1) What are learners' perceptions of the two literary genres in terms of language-related benefits?

2) What are learners' perceptions of the two literary genres in terms of 
non-language-related benefits?

3) What are the differences in their perceptions of the two genres?

\section{Methods}

\section{Participants}

The participants in this study were EFL learners in Hong Kong, either secondary four to secondary six students or graduates from secondary schools within six months of graduation. These participants had studied EFL for at least eight to 10 years. They were recruited via convenience and snowball sampling. A total of 1225 questionnaires were distributed, 1190 of which were valid (i.e. mostly or fully completed). The 1190 participants $\left(M_{\text {age }}=16.86, S D=1.39\right.$; males $=495$, females=691 $)$ were studying or had studied at at least 40 different secondary schools in different regions in Hong Kong ${ }^{1}$. This suggests a wide range of schools, including schools whose catchment areas include students from different SES groups and including girls', boys' and co-educational schools. We ascertained that all participants had taken either the ShS module or the PS module and thus had had experience with the genre before distributing the questionnaires to them.

\section{The questionnaire}

Two sets of questionnaires were compiled, one for ShS and another for PS. They were identical except for their focus, namely, ShS or PS. Participants' demographic characteristics were collected in Part I while the items in Part II of the questionnaire were substantive questions probing into participants' opinions, beliefs, interests, and views of the value of the two genres. This article reports findings from 27 items in Part II measuring learners' perceptions of the benefits of ShS or PS.

\subsection{Conceptual framework for item construction}

The use of literature in FL education for purposes that go beyond language proficiency enhancement is widely acknowledged. There is ample empirical evidence and much discussion about the use of literature to support non-language development such as affective and generic skills (e.g. Kim, 2004; Liaw, 2001; Urlaub, 2012; Yang, 2002). Facilitating learners' whole-person development is a key mission which teachers and schools endeavour to achieve nowadays ( $\mathrm{Chu}$, Reynolds, Tavares, Notari \& Lee, 2016), including in Hong Kong. It is therefore worthwhile investigating both perceived language- and non-language gains from literature in FL classrooms. Elements that might be important in some FL contexts, such as literary themes and literary history (e.g. Bloemert, Paran, Jansen, \& van de Grift 2019) were not included,

\footnotetext{
${ }^{1}$ As with the missing cases for gender, some participants did not put down their school names.
} 
as they are not a part of literature use in the EFL curriculum in Hong Kong (CDC \& HKEAA, 2014).

\subsection{Construction of items}

Constructing the 27 items began with content analysis, that is, identifying relevant phrases in key sources regarding language and non-language aspects of the use of literature in FLE, and producing items that referred to and used these phrases. The various sources included: Hong Kong curricular documents and guides such as the English language curriculum and assessment guide (secondary 4-6), published by the CDC and HKEAA (2014); the Senior Secondary Curriculum Guide and specific booklets accompanying the guide (CDC, 2009); various documents and notices on the website, New Academic Structure Web Bulletin for Senior Secondary Education and Higher Education (http://334.edv.hkedcity.net); and relevant questionnaire-based research (Davis et. al., 1992; Martin \& Laurie, 1993). The first two authors discussed the items and sought opinions from research colleagues and in-service teachers. Revisions were then made and a balance was struck between comprehensiveness and conciseness. One primary consideration whilst constructing the list of items was its applicability to other (E)FL contexts. The finalized inventory demonstrates this by being general and wide in coverage. For instance, in the language-related items, the four macro-skills, vocabulary, and grammar are included. Many items in the non-language-related items are essentially components in what is often called ' $21^{\text {st }}$-century competencies', a term widely used and acknowledged globally.

Figure 1 shows the 13 language-related items in the questionnaire. Figure 2 shows the 14 items about non-language-related benefits of the genres explored. Note that in both figures, the name of the module (in this case, 'Poems and songs') is highlighted for the participants' attention. As participants may not understand item 8 and 23, the translations in Chinese (the participants' L1) were given. 


\begin{tabular}{|c|c|c|c|c|c|}
\hline \multicolumn{6}{|c|}{$\begin{array}{l}\text { In your opinion, what are the effects that poems and songs in general have on your English } \\
\text { learning experience in the following areas? }\end{array}$} \\
\hline & $\begin{array}{l}\text { Strongly } \\
\text { Agree }\end{array}$ & Agree & Neutral & Disagree & $\begin{array}{l}\text { Strongly } \\
\text { Disagree }\end{array}$ \\
\hline \multicolumn{6}{|l|}{$\begin{array}{l}\text { I find that learning English through } \\
\text { poems and songs improves my: }\end{array}$} \\
\hline 1) listening abilities & 0 & 0 & 0 & 0 & 0 \\
\hline 2) speaking abilities & o & o & o & 0 & o \\
\hline 3) reading abilities & $\circ$ & ○ & $\circ$ & $\circ$ & $\circ$ \\
\hline 4) writing abilities & ○ & ○ & $\circ$ & ○ & $\circ$ \\
\hline 5) vocabulary & $\circ$ & $\circ$ & $\circ$ & ○ & $\circ$ \\
\hline 6) grammar & ० & ○ & ○ & ० & ○ \\
\hline 7) overall English proficiency & o & o & o & o & o \\
\hline $\begin{array}{l}\text { 8) language sensitivity/nuances of the } \\
\text { English language } \\
\text { [語文觸覺/英文微細差別的認知] }\end{array}$ & ० & ० & ० & ० & o \\
\hline 9) motivation to learn English & ० & ० & $\circ$ & $\circ$ & $\circ$ \\
\hline 10) confidence in using English & o & o & o & 0 & o \\
\hline 11) English for work in the future & ० & ० & ० & ० & ० \\
\hline $\begin{array}{l}\text { 12) English for pleasure and } \\
\text { entertainment in the future }\end{array}$ & ० & ० & ० & ० & ० \\
\hline $\begin{array}{l}\text { 13) English for further studies in the } \\
\text { future }\end{array}$ & ० & ० & ० & ० & o \\
\hline
\end{tabular}

Figure 1. The 13 language-related items in the questionnaire 


\begin{tabular}{|c|c|c|c|c|c|}
\hline \multicolumn{6}{|c|}{$\begin{array}{l}\text { In your opinion, what are the effects that poems and songs in general have on your Other } \\
\text { learning experience in the following areas? }\end{array}$} \\
\hline & $\begin{array}{l}\text { Strongly } \\
\text { Agree }\end{array}$ & Agree & Neutral & Disagree & $\begin{array}{l}\text { Strongly } \\
\text { Disagree }\end{array}$ \\
\hline \multicolumn{6}{|l|}{$\begin{array}{l}\text { I find that learning English through } \\
\text { poems and songs } \\
\text { improves/increases/helps my: }\end{array}$} \\
\hline 14) general education & o & o & o & o & ० \\
\hline $\begin{array}{l}\text { 15) knowledge of the world such as } \\
\text { others' lives and different cultures }\end{array}$ & ० & ० & $\circ$ & ० & ० \\
\hline $\begin{array}{l}\text { 16) greater understanding of humans' } \\
\text { thoughts and feelings }\end{array}$ & o & o & o & o & o \\
\hline 17) motivation for learning in general & ० & ० & ० & ○ & ○ \\
\hline $\begin{array}{l}\text { 18) preparation for work and } \\
\text { work-related training }\end{array}$ & ० & ० & ० & ० & ० \\
\hline 19) preparation for further studies & o & ○ & ○ & $\circ$ & ○ \\
\hline $\begin{array}{l}\text { 20) positive values and attitude (towards } \\
\text { life, working and learning) }\end{array}$ & ० & ० & ० & ० & ० \\
\hline 21) critical thinking skills & 0 & 0 & 0 & 0 & 0 \\
\hline 22) communication skills & 0 & 0 & 0 & 0 & 0 \\
\hline $\begin{array}{l}\text { 23) aesthetic / literary appreciation } \\
\text { [審美觀/文學欣賞] }\end{array}$ & ० & ० & ० & ○ & ० \\
\hline 24) learning how to learn & 0 & o & 0 & 0 & 0 \\
\hline 25) personal development & o & o & o & ० & ० \\
\hline 26) creativity & ○ & ○ & ○ & ○ & $\circ$ \\
\hline 27) problem-solving skills & o & o & 0 & 0 & 0 \\
\hline
\end{tabular}

Figure 2. The 14 non-language-related items in the questionnaire

\section{$\underline{2.3 \text { Pre-pilot \& Pilot }}$}

Two pre-pilots were conducted with two students through think-aloud interviews, recommended by Collins (2003) as one way of pretesting survey instruments through a focus on the "mental processes respondents use to answer survey questions" (p. 235) allowing the researcher to identify both overt and covert issues in the survey. The two respondents were given opportunities to practise thinking aloud before the pre-pilot. The pre-pilots were audio-recorded and informal interviews were conducted immediately afterwards. In general, the participants found the items clear but they commented that elaboration and clarification from the administrator were very important. Based on their suggestions, the questionnaires were lexically simplified, and translated and back-translated (when simplification could not be achieved).

Thirty student participants were then invited for the pilot study and informal 
group interviews were conducted with them after they completed the questionnaires. The participants thought that the 27 items were generally clear although they needed clarifications on a few items (e.g. the difference between English for further studies and preparation for further studies, the latter referring to, e.g., general skills/knowledge required for studying at the tertiary level). It was evident that guiding the students through the questionnaire (e.g. orally explaining each section and the items before the participants completed them) was essential.

\subsection{Administering the questionnaire}

The paper-and-pencil questionnaires were administered by teachers and the first author, who were physically present in the classrooms to provide clarifications and assistance. The time for completing the entire questionnaire was less than 25 minutes and no signs of fatigue were observed (see Dörnyei, 2010).

\section{Data Analyses}

After the questionnaires were collected, we conducted the process of "data cleaning" (Dörnyei, 2010, p. 88-89), which involves carefully checking the data collected to minimize errors which might distort later analyses. Questionnaires collected were scrutinized for conscientiousness; those that were suspicious and not completed seriously (e.g. ticking all "neutral" options indiscriminately) were discarded. Out of the 1225 questionnaires distributed, 1190 were valid (625 in ShS and 565 in PS), yielding a very high rate of $97.14 \%$.

Descriptive statistics such as central tendency (mean, median and mode), dispersion (standard deviation), minimum, maximum, and the percentiles were calculated, and independent samples t-tests were carried out to compare responses on the questionnaires for the two different genres. We then conducted an exploratory factor analysis with geomin rotation using Mplus (Muthén \& Muthén, 1998-2012) to explore the factor structure of the data. This analysis aims to determine the nature and number of latent variables that explain variance and covariance among the set of observed indicators. Of the various commonly available methods, we chose to use parallel analysis to extract the number of factors because it has been demonstrated to be the most accurate one (Schmitt, 2011). Parallel analysis generates a series of random data sets having the same sample size and number of variables as the original data set (Horn, 1965). If the eigenvalues of the factors obtained from the original data are larger than those obtained from the randomly generated data, the factors are retained. Based on this criterion, parallel analysis suggested a three-factor solution for the data with eigenvalues of 11.398, 1.484 and 1.356 (Table 3). These three factors had high Cronbach's alpha values of $.81, .88$, and .91 respectively. Deleting any item 
from any factor was found to lower the reliability of that factor. This model enables us to present a more succinct summary of learners' views.

\section{Results}

1 Descriptive statistics (individual items)

Table 1 shows the descriptive statistics for the 13 individual language-related items for the two genres, as well as the differences between participants' views of the two genres. As can be seen, respondents in general view $\mathrm{ShS}$ as providing (slightly) positive benefits, apart from listening abilities $(M=2.91)$. Vocabulary and reading abilities are the areas perceived to be most improved $(M \geq 4)$, followed by writing abilities, grammar, and overall English proficiency (all $M s>3.5$ ). In contrast, respondents in general hold mixed views of the benefits of PS to their English learning. As in ShS, PS are perceived by learners to be most effective $(M \geq 3.5)$ in improving their reading abilities and vocabulary. However, of the 13 items in this section, four were rated negatively $(M<3)$, namely grammar, confidence in using English, English for work and English for further studies. The learners thus do not believe that PS play a role in facilitating their development in these areas.

\begin{tabular}{|c|c|c|c|c|c|}
\hline & ShS & PS & & & \\
\hline & $M(S D)$ & $M(S D)$ & $p$ & $t(d f)$ & $d$ \\
\hline Listening abilities & $2.91(0.93)$ & $3.37(1.01)$ & $<.001$ & $-8.18(1150.84)$ & 0.48 \\
\hline Speaking abilities & $3.17(0.93)$ & $3.30(1.00)$ & .021 & $-2.319(1150.98)$ & 0.14 \\
\hline Reading abilities & $4.00(0.73)$ & $3.50(0.91)$ & $<.001$ & $10.19(1082.36)$ & 0.60 \\
\hline Writing abilities & $3.79(0.82)$ & $3.07(1.01)$ & $<.001$ & $13.58(1087.49)$ & 0.79 \\
\hline Vocabulary & $4.03(0.73)$ & $3.75(0.89)$ & $<.001$ & $5.85(1094.85)$ & 0.34 \\
\hline Grammar & $3.54(0.83)$ & $2.82(0.95)$ & $<.001$ & $13.97(1184)$ & 0.81 \\
\hline Overall English proficiency & $3.59(0.72)$ & $3.37(0.82)$ & $<.001$ & $4.72(1121.74)$ & 0.28 \\
\hline $\begin{array}{l}\text { Language sensitivity / } \\
\text { nuances of the English } \\
\text { language }\end{array}$ & $3.40(0.80)$ & $3.26(0.95)$ & .007 & $2.71(1104.06)$ & 0.16 \\
\hline Motivation to learn English & $3.33(0.86)$ & $3.07(1.04)$ & $<.001$ & $4.69(1097.40)$ & 0.27 \\
\hline Confidence in using English & $3.24(0.88)$ & $2.90(1.00)$ & $<.001$ & $6.16(1131.78)$ & 0.36 \\
\hline English for work & $3.21(0.91)$ & $2.71(1.07)$ & $<.001$ & $8.58(1106.11)$ & 0.50 \\
\hline $\begin{array}{l}\text { English for pleasure and } \\
\text { entertainment }\end{array}$ & $3.38(0.88)$ & $3.20(1.10)$ & .002 & $3.09(1075.17)$ & 0.18 \\
\hline English for further studies & $3.40(0.87)$ & $2.99(1.01)$ & $<.001$ & $7.48(1185)$ & 0.43 \\
\hline
\end{tabular}

Table 1. Descriptive statistics and results of independent t-tests for between-group differences in perception of language-related benefits of ShS/PS 
Table 2 shows the descriptive statistics for the 14 individual non-language-related items for the two genres, as well as the differences between learners' views of the two genres. For ShS, all items are rated from slightly positive to positive and the range is rather narrow (from 3.12 to 3.62 ). The most positively perceived areas (i.e. $M \geq 3.5$ ) are knowledge of the world and creativity. For PS, respondents in general hold rather diverse views (ranging from negative to positive) towards different areas, and the range is wider (from 2.49 to 3.45) than that in ShS. Knowledge of the world, greater understanding of humans' thoughts and feelings, and creativity all have means higher than 3.3. However, the means of seven of the 14 items are below the middle score of 3 . The items viewed particularly unfavourably include problem-solving skills $(M=2.49)$, preparation for work and work-related training $(M=2.74)$, preparation for further studies $(M=2.80)$ and learning how to learn $(M=2.82)$. A notable item is aesthetic/literary appreciation, which has the highest SD of 1.14, indicating great variation in the learners' perception of the effect of PS on promoting aesthetic/literary appreciation.

\begin{tabular}{|c|c|c|c|c|c|}
\hline & ShS & PS & & & \\
\hline & $M(S D)$ & $M(S D)$ & $p$ & $t(d f)$ & $d$ \\
\hline General education & $3.47(0.75)$ & $3.17(0.86)$ & $<.001$ & $6.40(1185)$ & 0.37 \\
\hline $\begin{array}{l}\text { Knowledge of the world such as } \\
\text { others' lives and different cultures }\end{array}$ & $3.52(0.80)$ & $3.45(0.97)$ & .199 & $1.29(1094.01)$ & 0.08 \\
\hline $\begin{array}{l}\text { Greater understanding of humans' } \\
\text { thoughts and feelings }\end{array}$ & $3.31(0.83)$ & $3.37(1.00)$ & .255 & $-1.14(1101.59)$ & 0.07 \\
\hline Motivation for learning in general & $3.33(0.79)$ & $2.99(0.94)$ & $<.001$ & $6.87(1184)$ & 0.40 \\
\hline $\begin{array}{l}\text { Preparation for work and } \\
\text { work-related training }\end{array}$ & $3.19(0.84)$ & $2.74(0.96)$ & $<.001$ & $8.53(1117.84)$ & 0.50 \\
\hline Preparation for further studies & $3.29(0.86)$ & $2.80(0.98)$ & $<.001$ & $9.02(1127.54)$ & 0.53 \\
\hline $\begin{array}{l}\text { Positive values and attitude } \\
\text { (towards life, working and } \\
\text { learning) }\end{array}$ & $3.44(0.81)$ & $3.14(0.99)$ & $<.001$ & $5.79(1079.05)$ & 0.34 \\
\hline Critical thinking skills & $3.37(0.85)$ & $3.02(1.04)$ & $<.001$ & $6.33(1085.68)$ & 0.37 \\
\hline Communication skills & $3.34(0.89)$ & $2.92(1.01)$ & $<.001$ & $7.57(1182)$ & 0.44 \\
\hline Aesthetic / literary appreciation & $3.23(0.94)$ & $3.29(1.14)$ & .401 & $-0.84(1091.84)$ & 0.05 \\
\hline Learning how to learn & $3.25(0.86)$ & $2.82(0.96)$ & $<.001$ & $8.15(1127.35)$ & 0.48 \\
\hline Personal development & $3.32(0.82)$ & $2.96(1.06)$ & $<.001$ & $6.46(1048.69)$ & 0.28 \\
\hline Creativity & $3.62(0.89)$ & $3.31(1.05)$ & $<.001$ & $5.45(1107.68)$ & 0.32 \\
\hline Problem-solving skills & $3.12(0.88)$ & $2.49(1.04)$ & $<.001$ & $11.07(1100.50)$ & 0.65 \\
\hline
\end{tabular}


Table 2. Descriptive statistics and results of independent t-tests for between-group differences in perception of non-language-related benefits of ShS/PS

\section{Differences between learners'views of ShS and PS}

As Tables 1 and 2 show, there are differences in students' perception of the effects of ShS and of PS on their learning in the 27 areas (i.e. the 13 English-related and 14 non-English-related aspects), and these differences are mostly statistically significant. Only three out of 27 items are not associated with statistical significance (i.e. $p>.05$ ). These items are: knowledge of the world such as others' lives and different cultures, which is among the few rated most positively ( $M s$ around 3.5) by the two groups of respondents, and improvement in their greater understanding of humans' thoughts and feelings as well as aesthetic / literary appreciation (both of whose $M s=$ around 3.2 to $3.4)$.

The greatest differences ( $p<.001, d$ approaching 0.5 or greater) lie in the following items: listening, reading abilities, writing abilities, grammar, English for work, preparation for work and work-related training, preparation for further studies, learning how to learn, and problem-solving skills. The Ms of these items in ShS are all higher than the corresponding items in PS, except for listening abilities. Also, in these 27 items, the opinions in $\mathrm{ShS}$ are more centralized as indicated by the relatively lower $S D$ (with only four items higher than 0.9 and the highest being 0.94 in aesthetic/literary appreciation) compared to PS, (with 24 items higher than 0.9 , with 13 items higher than 1.0, and the highest being 1.14, likewise for aesthetic/literary appreciation).

\section{The three underlying constructs of learners' views of ShS/PS}

The results of parallel analysis, presented in Table 3, showed that the 27 items were explained by three latent factors. The factor loadings ranged from .34 to .78 . The first factor with the highest Eigenvalue of 11.398 comprises only reading, writing, vocabulary and grammar. The second factor contains a mixture of elements including (spoken) language proficiency (e.g. listening abilities), psychology (e.g. motivation for learning in general), aesthetic (e.g. aesthetic / literary appreciation) and cognitive development (e.g. greater understanding of humans' thoughts and feelings). The third factor is composed of a number of generic skills (e.g. communication skills) and work- and study-related aspects (e.g. English for work in the future). The three factors revealed the pattern of relationships underlying learners' perceptions of the benefits of $\mathrm{PS} / \mathrm{ShS}$. Especially noteworthy is the fact that language-related items connected to spoken language are closely connected to items that looked at motivation and confidence, as well as some other non-language-related features within factor two. 


\begin{tabular}{|c|c|c|c|}
\hline & \multicolumn{3}{|c|}{ Geomin Rotated Loadings } \\
\hline & $\begin{array}{l}\text { Factor } 1 \\
\text { (Written) Language } \\
\text { Proficiency }\end{array}$ & $\begin{array}{l}\text { Factor } 2 \\
\text { (Spoken) Language } \\
\text { Proficiency, } \\
\text { psychology, aesthetic } \\
\text { and cognitive } \\
\text { development }\end{array}$ & $\begin{array}{l}\text { Factor } 3 \\
\text { Generic skills, work } \\
\text { and studies }\end{array}$ \\
\hline Reading & .60 & & \\
\hline Writing & .64 & & \\
\hline Vocabulary & .57 & & \\
\hline Grammar & .51 & & \\
\hline Listening & & .63 & \\
\hline Speaking & & .43 & \\
\hline Overall Proficiency & & .48 & \\
\hline Language Sensitivity & & .57 & \\
\hline Motivation (English) & & .61 & \\
\hline Confidence (English) & & .38 & \\
\hline English for Pleasure & & .56 & \\
\hline English for Work & & & .62 \\
\hline English for Studies & & & .51 \\
\hline World Knowledge & & .54 & \\
\hline Human Thoughts & & .64 & \\
\hline Motivation (General) & & .46 & \\
\hline Aesthetic Appreciation & & .59 & \\
\hline Creativity & & .34 & \\
\hline General Education & & & .37 \\
\hline Preparation for Work & & & .78 \\
\hline Preparation for Studies & & & .78 \\
\hline Positive Values & & & .40 \\
\hline Critical Thinking & & & .53 \\
\hline Communication & & & .58 \\
\hline Learning to Learn & & & .47 \\
\hline Personal Development & & & .51 \\
\hline Problem-Solving & & & .67 \\
\hline Eigenvalue & 11.398 & 1.484 & 1.356 \\
\hline Cronbach's $\alpha$ & .81 & .88 & .91 \\
\hline
\end{tabular}

Table 3. Parallel Analysis of the 27 items 
Based on the three-factor model, the descriptive statistics and differences between the two genres are presented in Table 4. The results show that the participants held a neutral to slightly positive view about the benefits of PS and ShS. ShS were thought to be especially useful for their (written) language proficiency (i.e. Factor 1; $M=$ 3.84). The PS participants were neutral to slightly negative about PS's value in future work/studies and developing their generic skills (i.e. Factor 3). PS and ShS were perceived significantly differently in all three factors.

\begin{tabular}{|c|c|c|c|c|c|c|c|}
\hline & \multicolumn{2}{|c|}{$\operatorname{ShS}(n=625)$} & \multicolumn{2}{|c|}{$P S(n=565)$} & \multirow[b]{2}{*}{$t(d f)$} & \multirow[b]{2}{*}{$p$} & \multirow[b]{2}{*}{$d$} \\
\hline & $M$ & $S D$ & $M$ & $S D$ & & & \\
\hline Factor 1 & 3.84 & 0.62 & 3.29 & 0.73 & $14.10(1107.72)$ & $<.001$ & 0.83 \\
\hline Factor 2 & 3.32 & 0.56 & 3.24 & 0.69 & $2.35(1092.91)$ & 0.019 & 0.13 \\
\hline Factor 3 & 3.31 & 0.58 & 2.89 & 0.72 & $10.98(1080.73)$ & $<.001$ & 0.65 \\
\hline
\end{tabular}

Table 4. Descriptive statistics and t-tests for the three factors

\section{Discussion}

\section{Perceived English-related benefits}

With previous studies suggesting that learners are positive about gains in general language proficiency from studying literature such as vocabulary (e.g. Bloemert, Paran, Jansen, \& van de Grift, 2019; Yang, 2001) and reading skills (Duncan \& Paran 2017), we sought to explore this area further by measuring and analyzing learners' perception of the differential effects of different literary genres on multiple areas related to language learning.

The analysis of the items in the questionnaires revealed that participants think that ShS bring about a (slightly) positive effect on 12 out of 13 aspects of English learning, the most notable of which are vocabulary and reading abilities $(M s \geq 4)$. Listening abilities was the only item rated rather negatively $(M=2.91)$. This is understandable as reading ShS provides little practice in listening, unless learners engage in, for instance, listening to audiobooks. Overall, learners' positive opinions of literature being effective in enhancing their FL proficiency are in agreement with scholars such as Paran (2012) and Van (2009).

As for PS, we found that on nine of the 13 items, the respondents generally think that PS can also effect improvement on their English. Reading abilities and vocabulary are again rated the most effective of all albeit with lower mean scores (Ms $\geq 3.5$ ) than those in ShS. It is quite obvious that PS are not perceived to be effective for learning English for work in the future $(M=2.71 ; S D=1.07)$, and English for further studies in the future $(M=2.99 ; S D=1.01)$ unless, for instance, learners can 
envisage their engagement with poetry later (e.g. majoring in literature at universities or becoming a writer), which is unlikely for the vast majority. In addition, the participants do not think PS are effective for enhancing their grammar $(M=2.82 ; S D$ $=0.95)$. It is noteworthy that learners may not realize that in reality grammar learning can be enhanced through engagement with poetry, as demonstrated by Hanauer (2001), where learners were found to show a high level of noticing of unusual grammatical usage. Learners may not be aware of the implicitness of the grammatical analyses which readers naturally perform when reading a poem.

Another remarkable area is confidence in using English $(M=2.9 ; S D=1)$. From the mean score, the learners do not generally think PS play a role in developing their confidence. Although there are a number of scholars and empirical studies suggesting a link between literature and learners' motivation (e.g. Bloemert, Jansen and Paran, 2019; Wheeler, 1997), there are only a few which have examined the relationship between literature and confidence. In Shelton-Strong (2012) and Ghiabi (2014), learners were found to have gained confidence after reading unabridged novels. The discrepancy between the positive results in these two studies and the present study might be because of the different genres. The ShS participants do show slightly positive views of their gain in confidence $(M=3.24 ; S D=0.88)$ in this study. This seems to imply that prose may be more effective than poetry in developing learners' confidence.

The comparison between the two genres highlights the great differences in perception in a great number of items. The majority of the language-related items (12 out of 13) were associated with statistically significant differences between the genres, with small to large effect sizes. ShS have higher mean scores than PS in all areas apart from listening abilities. The higher score in listening in PS is very likely due to listening to songs. Relatively large effect sizes $(d \geq 0.6)$ in the differences were found in reading abilities, writing abilities, and grammar. Although a significant difference in reading abilities is found, both groups rated this item rather positively ( $M$ in $\mathrm{ShS}=4$; $M$ in PS =3.5). This is not quite the case for writing and grammar. Respondents perceive writing $(M=3.79 ; S D=0.82)$ and grammar $(M=3.54 ; S D=0.83)$ rather positively in ShS. However, these two areas are only rated neutral to slightly negative in PS - writing $(M=3.07 ; S D=1.01)$ and grammar $(M=2.82 ; S D=0.95)$. ShS, as other types of prose, on the other hand, are generally written in the common non-poetic syntax which learners are expected to achieve, hence perhaps deemed more relevant to developing their grammatical competence. In this respect, our findings corroborate other studies which report that poetry is used less than other genres, as well as arousing conflicting views by teachers and learners. Duncan and Paran (2017) found that poetry was a neglected genre in their teacher questionnaire; in 
interviews with teachers they found greatly divergent views of poetry; and students believed that poetry was more difficult than other genres and required greater interpretive skills. However, in the Maltese context, Xerri (2016) found that the majority of his interviewees and survey participants ascribed importance to poetry and thought it should be studied. This may be an indicator of the importance of the educational context to the views that learners and teachers have of literature in general and of specific genres in particular.

\section{Perceived non-English-related benefits}

Learners' perception of the effects of ShS on the 14 items of non-English learning experience is slightly positive across all the items (Ms ranging from 3.12 to 3.62). In particular, positive items include general education, knowledge of the world such as others' lives and different cultures, positive values and attitude (towards life, working and learning), and creativity (all $M s>3.4$ ). The least positive one is problem-solving skills $(M=3.12)$ due perhaps to their irrelevance to ShS generally unless, for instance, learners are familiar with and thought of certain sub-genres under ShS - for example, detective ShS, which may promote problem-solving skills. In general, learners are of the opinion that ShS somewhat effectively facilitate their development in these non-language-related areas, which are often neglected and seen as subordinate to proficiency in FLE (Paran, 2008; Sivasubramaniam, 2006). The findings here seem to support the claim that ShS as a literary genre promotes whole-person development and generic skills (e.g. Gilroy \& Parkinson, 1996), which is often overshadowed by functionality (Choo, 2011), overwhelming focus on FL proficiency (Paran, 2008), and “calculative-thinking” culture (Sivasubramaniam, 2006, p. 256) in FLE.

There is much greater variation in perception of the effects of PS (Ms across the 14 items ranging from 2.49 to 3.45$)$. The most positive effects $(M \gtrsim 3.3$; with medians and modes $=4$ ) include: Knowledge of the world such as others' lives and different cultures, creativity, greater understanding of humans' thoughts and feelings, and aesthetic / literary appreciation. Although one may expect learners to see PS more positively than ShS in enhancing aesthetic/literary appreciation in light of the poetic language in PS, the difference here was minimal and not statistically significant ( $M$ in $\mathrm{PS}=3.29 ; M$ in $\mathrm{ShS}=3.23, p=.40$ ). A possible reason for this may be that literary appreciation was not the focus when learners engaged with PS. Similar to ShS, learners do not see the effect of PS on their problem-solving skills $(M=2.49 ; S D=$ $1.04)$, as well as on other areas such as learning how to learn $(M=2.82 ; S D=0.96)$, preparation for work and work-related training $(M=2.74 ; S D=0.96)$, and future studies $(M=2.80 ; S D=0.98)$. While the lower value learners perceive of PS in preparation for work, training and studies can somewhat easily be justified, it is 
interesting that problem-solving skills and learning how to learn are not perceived to be relevant (e.g. through reading between the lines and discover the gist and meanings in poems and lyrics). This has implications for FL teachers as to the areas they can focus on when using literature in FLE.

It is worth underlining that the three out of 27 items not associated with differences between the two genres (all non-language-related; see Tables 1 and 2) may point us towards some of the more general value of literary texts. Non-canonical ShS and PS are common literary materials employed in FL classrooms; others not investigated, we posit, may be viewed as similar to these two genres (e.g. novels and diary entries somewhat similar to ShS; slogans and advertisements somewhat similar to PS). If what we maintain is true, knowledge of the world, understanding of humans' thoughts and feelings, and aesthetic/literary appreciation are three aspects which learners generally viewed slightly positively towards literature at large. These may be named unique benefits of literature in FLE.

It is also worth mentioning that the $S D s$ are generally higher across the items in PS than those in ShS. None of the SDs are higher than or equal to one in ShS, but as many as seven items in PS have values of one or higher. This indicates that learners have greater variation in judgment of the effects of PS on their learning. The great difference in perception may be partly attributed to their different experiences with the genre. For example, the greatest $S D$ was found in the item on aesthetic / literary appreciation in the PS questionnaire $(M=3.29$, median $=$ mode $=4, S D=1.14)$. In this item, $8.7 \%$ of the respondents chose strongly disagree; $17.0 \%$ chose disagree; $22.7 \%$ chose neutral; $39.8 \%$ chose agree and $11.5 \%$ chose strongly agree. Those who responded very favourably to this item might have had great experiences with appreciating PS, for instance, in the PS lessons or reading the lyrics closely when they sing or even, when they were young, chanting nursery rhymes. In contrast, those who are neutral or negative towards this item may not be aware of the aesthetic / literary values and do not see much in PS worth appreciating. They could simply be treating PS as another piece of text (e.g. in reading comprehension exercises) or focus on the song melodies and rhythms rather than the lyrics. Further research on individuals (possibly through case studies) is needed to understand the reasons for this wide variation.

\section{Overview of participants'views}

The parallel analysis reveals that the inventory of items used in the questionnaire can be presented by three factors. The participants were (slightly) positive towards both ShS and PS in factor one, which we have named "(Written) language proficiency", and in factor two, which we have named "(Spoken) language proficiency, psychology, 
aesthetic and cognitive development', and which included items related to spoken language, items connected to motivation and confidence, and items connected to aesthetic appreciation and cognitive development. ShS are perceived to be especially useful in developing learners' written and overall English proficiency (factor 1). As for factor 3 - which we have named "generic skills, work and studies", ShS were viewed slightly positively while PS slightly negatively. The analysis shows that the value of different genres is perceived differently: ShS are valued more than PS and the difference is statistically significant, with effect sizes that are medium/large for factors 1 and 3 and small for factor 2. This supports the need to be cautious when making claims about the value of literature in general and the need to distinguish between the use of different genres.

Notably, the structure of our data is different from that in Bloemert, Jansen, and Paran (2019), who found a clear division between a literature factor, a language factor, and a personal development factor. However, it is important to note that Bloemert, Jansen, and Paran (2019) was carried out in a context where there is a much stronger focus on literary issues - e.g. themes, literary devices, historical background - than in the Hong Kong context. This interpretation of the reasons for the difference is borne out by the fact that the factor with the highest eigenvalue in Bloemert, Jansen and Paran (2019) was a literature factor, whereas in our study the language factor was the one with the highest eigenvalue. It is noteworthy that two of the factors in our data were language related.

\section{Conclusion}

This large-scale study examined Hong Kong EFL learners' perception of the benefits of ShS and PS through a 27-item questionnaire which looked at language- and non-language-related aspects. All in all, ShS and PS, two frequently-occurring genres in the FLE classroom, are perceived by learners in this context to be somewhat conducive to their language development and also non-language development to a certain extent. ShS seem to be more positively viewed than PS, yet there are areas perceived to be beneficial in both genres. From the learners' perspective, it seems that ShS are regarded as contributing to both language-related and non-language-related development. The differences between perception of the two genres has implications for frontline teachers and curriculum designers in FLE, for example in terms of choice of materials or in the pedagogic approach and the way in which benefits are made explicit to learners. In addition to the findings from 27 items, we presented a three-factor model of learners' perceptions of literature. All three factors were perceived differently in terms of their benefits, with medium to large effects between the two genres on Factor 1 ((Written) Language Proficiency) and Factor 3 (Generic 
Skills, Work and Studies), and a small effect on Factor 2 ((Spoken) Language Proficiency, Psychology, Aesthetic and Cognitive Development).

Our study contributes to the body of quantitative empirical research into literature in FLE that is beginning to be conducted in different educational systems. Indeed, the context of our study is an important consideration in understanding our results. The context determined the definition of literature underlying the study, and will have contributed to what our learners perceived as short stories or as poems and songs. Our findings thus cast light on this specific context, and similar studies in other educational systems are needed for more general conclusions to be reached.

Researchers may also consider investigating learners' background variables (e.g. SES and previous FL achievements) together with their views to yield more detailed findings. An additional limitation is the lack of depth in learners' responses in the type of questionnaire that we employed. A possible solution could be inviting some participants for post-questionnaire interviews, especially those who have different views as shown in the questionnaires so that (the differences in) perceived benefits can be elaborated. In addition, we only investigated learners' perceptions in two popular genres, namely short stories (prose) and poems and songs (poetry). Further studies may investigate learners' views on other literary genres used in FLE such as plays or novels, employing the same instrument in this study for comparison. The presence and absence of melody in songs and poems respectively warrant a closer investigation which compares learners' views of the two similar genres. It will also be research-worthy to explore teachers' views, since their views may well influence their choice of materials as well as pedagogical approaches. Future studies may employ the inventory to examine teachers' perceptions and compare theirs with the students', thereby generating a more comprehensive profile of stakeholders' views of the benefits of literature in FLE.

We have shown that while there are specific benefits seemingly shared by literary genres, differences among these genres also exist. In future research, researchers should consider the existence of different genres rather than investigating 'literature', which can be understood in multiple senses and comprises different genres. Another possibility for future research would take into account learner characteristics, including proficiency and achievement, to see whether different learners respond to literature in different ways. Finally, our questionnaire, though partly rooted in the Hong Kong curriculum, has the potential of being adapted to other EFL situations; in addition, its construction could serve as a model for constructing instruments for research in other contexts. 


\section{References}

Akyel, A. \& Yalçin, E. (1990) Literature in the EFL class: a study of goal-achievement incongruence. ELT journal, 44(3), 174-80.

Bland, J. (Ed.). Using literature in English language education. Challenging reading for 8-18 year olds. London: Bloomsbury.

Bloemert, J., Jansen, E., \& van de Grift, W. (2016). Exploring EFL literature approaches in the Dutch secondary education. Language, Culture and Curriculum 29(2), 169-188.

Bloemert, J., A. Paran, E. Jansen \& W. van de Grift. 2019. Students' perspective on the benefits of EFL literature education. The Language Learning Journal 47 (3, 371-384. DOI: 10.1080/09571736.2017.1298149.

Bloemert, J., Jansen, E., and Paran, A. 2019. Student motivation in Dutch secondary school EFL literature lessons. Applied Linguistics Review, AOP. DOI:

https://doi.org/10.1515/applirev-2019-0041

Bobkina, J., \& Dominguez, E. (2014). The use of literature and literary texts in the EFL classroom: between consensus and controversy. International Journal of Applied Linguistics \& English Literature, 3(2), 248-260.

Brown, A. V. (2009). Students' and teachers' perceptions of effective foreign language teaching: A comparison of ideals. The Modern Language Journal, 93(1), 46-60.

Carless, D., \& Harfitt, G. (2013). Innovation in secondary education: A case of curriculum reform in Hong Kong. In K. Hyland and L. C. Wong (Eds.), Innovation and Change in English Language Education (pp. 172-185). Milton Park, Abingdon, Oxon: Routledge.

Carter, R. (2007). Literature and language teaching 1986-2006: A review. International Journal of Applied Linguistics, 17(1), 3-13.

Carter, R., \& Long, M. (1991). Teaching literature. Burnt Mill, Harlow, Essex: Longman.

Cheung, A. and Hennebry-Leung, M. 2020. Exploring an ESL teachers' (sic) beliefs and practices of teaching literary texts: A case study in Hong Kong. Language Teaching Research, Advance Publication, 1-26. doi:10.1177/1362168820933447.

Choo, S. S. (2011). On literature's use (ful/less) ness: reconceptualizing the literature curriculum in the age of globalization. Journal of Curriculum Studies, 43(1), 47-67.

Chu, S. K. W., Reynolds, R. B., Tavares, N. J., Notari, M. \& Lee, C. W. Y. (2016). 21 st century skills development through inquiry-based learning: From theory to practice. Singapore: Springer Verlag

Collins, D. (2003). Pretesting survey instruments: An overview of cognitive methods. 
Quality of life research, 12(3), 229-238.

Curriculum Development Council. (2009). Senior secondary curriculum guide. Accessed $5^{\text {th }}$ May, 2020

https://cd1.edb.hkedcity.net/cd/cns/sscg_web/html/english/main00.html

Curriculum Development Council \& Hong Kong Examinations and Assessment Authority. (2014). English language curriculum and assessment guide (secondary 4-6). Hong Kong: Government Logistics Department.

Davis, J. N., Kline, R. R., Gorell, L. C., \& Hsieh, G. (1992). Readers and foreign languages: A survey of undergraduate attitudes toward the study of literature. The Modern Language Journal, 76(3), 320-332.

Diaz-Santos, G. (2000). Technothrillers and English for science and technology. English for Specific Purposes, 19(3), 221-236.

Dörnyei, Z. (2010). Questionnaires in second language research: Construction, administration, and processing ( $2^{\text {nd }}$ ed.). London: Routledge.

Duncan, S. \& Paran, A. 2017. The effectiveness of literature on acquisition of language skills and intercultural understanding in the high school context. Report for the IB Organisation. Available on:

http://www.ibo.org/contentassets/1fcefe0df17448bebe6781ea0396adff/effect-of-li terature-on-language-acquisition-final-report.pdf

Duncan, S. \& Paran, A. 2018. Negotiating the challenges of reading literature: Teachers reporting on their practice. In: J. Bland (ed.). Using literature in English language education. Challenging reading for 8-18 year olds. 243-269. London: Bloomsbury.

Ghiabi, S. (2014). Investigation of the effect of using a novel as an extensive reading on students' attitudes and reading ability. International Journal of Applied Linguistics \& English Literature, 3(4), 55-64.

Gilroy, M. \& Parkinson, B. (1996). Teaching literature in a foreign language. Language Teaching, 29(4), 213-225.

Hall, G. (2015). Literature in language education ( $2^{\text {nd }}$ ed.). Basingstoke, Hampshire; New York: Palgrave Macmillan.

Hall, G. (2016). Using literature in ELT. In G. Hall (Ed.), The Routledge handbook of English language teaching (pp. 456-469). London, New York: Routledge.

Hanauer, D. I. (2001). The task of poetry reading and second language learning. Applied linguistics, 22(3), 295-323.

Harlow, L. L. \& Muyskens, J. M. (1994). Priorities for intermediate-level language instruction. The Modern Language Journal, 78(2), 141-154.

Heilbronn, R. (2019.) Literature, culture and democratic citizenship. In: F. Diamantidaki (ed.) Teaching literature in modern foreign languages. (pp. 9-23). 
London: Bloomsbury.

Hirvela, A. (2005). ESL students and the use of literature in composition courses.

Teaching English in the Two-Year College, 33(1), 70-77.

Horn, J. L. (1965). A rationale and a test for the number of factors in factor analysis.

Psychometrika, 30,179-185.

Jones, C.(ed.) 2019. Literature, spoken language and speaking skills in second language learning. Cambridge: Cambridge University Press.

Kim, M. (2004). Literature discussions in adult L2 learning. Language and Education, $18(2), 145-166$.

Kirchhoff, P. (2016). Is there a hidden canon of English literature in German secondary schools. In F. Klippel, (Ed.), Teaching Languages - Sprachen Lehren (pp. 229-248). Münster: Waxmann.

Kuze, K. (2015). Using short stories in university composition classrooms. In M. Teranishi, Y. Saito, \& K. Wales (Eds.), Literature and language learning in the EFL Classroom (pp. 182-196). Basingstoke, Hampshire; New York, NY: Palgrave Macmillan.

Liaw, M. L. (2001). Exploring literary responses in an EFL classroom. Foreign language annals, 34(1), 35-45.

Luukka, E. (2019). Selection, Frequency, and Functions of Literary Texts in Finnish General Upper-Secondary EFL Education. Scandinavian Journal of Educational Research, 63(2), 198-213.

Martin, A. L., \& Laurie, I. (1993). Student views about the contribution of literary and cultural content to language learning at intermediate level. Foreign Language Annals, 26(2), 188-207.

Muthén, L. K., \& Muthén, B. O. (1998-2012). Mplus user's guide (7 $7^{\text {th }}$ ed). Los Angeles, CA: Muthén \& Muthén.

$\mathrm{Ng}$, P. T. (2004). Students' perception of change in the Singapore education system. Educational Research for Policy and Practice, 3(1), 77-92.

Nguyen, H. T. T. (2016). How does an interactive approach to literary texts work in an English as a foreign language context? Learners' perspectives in close-up. Innovation in Language Learning and Teaching 10(3). 171-189.

Nguyen, P. N. T., Janssen, T., Rijlaarsdam, G., \& Admiraal, W. (2016). Effects of self-questioning on EFL students' engagement in literary reading. Cultura y Educación, 28(4), 702-737.

Paran, A. 2006. The Stories of Literature and Language Teaching. In: A. Paran (ed.) Literature in Language Teaching and Learning. Case Studies in TESOL. 1-10. Washington: TESOL.

Paran, A. 2008. The Role of Literature in Instructed foreign language learning and 
teaching: An Evidence-based survey. Language Teaching, 41 (4), pp. 465-496.

Paran, A. 2012. Language skills: Questions for Teaching and Learning. ELT Journal, 67: 4, 450-458.

Paran, A., Spöttl, C., Ratheiser, U., and Eberharter, K. 2021. Measuring literary competences in SLA. In: P. Winke \& T. Brunfaut (eds.) The Routledge Handbook of Second Language Acquisition and Language Testing. 326-337. New York: Routledge.

Schmidt, I. (in preparation) Shakespeare in the foreign language classroom: results of an empirical study. In: A. Paran, (ed.) Shakespeare and the Second Language Learner.

Schmitt, T. A. (2011). Current methodological considerations in exploratory and confirmatory factor analysis. Journal of Psychoeducational Assessment, 29(4), 304-321.

Shelton-Strong, S. J. (2012). Literature circles in ELT. ELT Journal, 66(2), 214-223.

Sivasubramaniam, S. (2006). Promoting the prevalence of literature in the practice of foreign and second language education: Issues and insights. Asian EFL journal, $8(4), 254-273$.

Struyven, K., Dochy, F., \& Janssens, S. (2005). Students' perceptions about evaluation and assessment in higher education: A review. Assessment \& Evaluation in Higher Education, 30(4), 325-341.

Teranishi, M., Saito, Y. and Wales, K. 2015. Literature and language learning in the EFL Classroom. Basingstoke, Hampshire; New York, NY: Palgrave Macmillan.

Ur, P. (2020). Review of S. Walsh and S. Mann (eds.) The Routledge Handbook of English Language Teacher Education. ELT Journal 74 (4), 518-521. https://doi.org/10.1093/elt/ccaa041.

Urlaub, P. (2012). Reading strategies and literature instruction: Teaching learners to generate questions to foster literary reading in the second language. System, 40(2), 296-304.

Van, T. T. M. (2009). The relevance of literary analysis to teaching literature in the EFL classroom. English Teaching Forum, 47(3), 2-9, 17.

Viana, V., \& Zyngier, S. (2019). Creative writing and iconicity in English as a foreign language. New Writing, 16(1), 38-49.

Wheeler, J. M. (1997). Poems in the language classroom. In A. Mok (Ed.), English language enrichment programme resource book (pp. 30-40). Hong Kong: INSTEP

Williams, M., and Burden, R. (1997). Psychology for language teachers. A social constructivist approach. Cambridge: Cambridge University Press.

Wolthuis, F., Bloemert, J., Tammenga-Helmantel, M. and Paran, A. 2019. A 
curriculum in transition: TL/L1 use in Dutch EFL literature lessons. Language, Culture and Curriculum. Open

Access. https://doi.org/10.1080/07908318.2019.1697279

Xerri, D. (2016). 'Living in a house without mirrors': Poetry's Cachet and Student Engagement. Anglica: An International Journal of English Studies. 25(1): 271-286.

Yang, A. (2001). Reading and the non-academic learner: A mystery solved. System 29(4), 450-460.

Yang, A. (2002). Science fiction in the EFL class. Language, Culture and Curriculum $5(1), 50-60$. 


\section{Appendices}

An example of teaching material for Short Stories

https://www.edb.gov.hk/attachment/en/curriculum-development/kla/eng-edu/Short $\% 2$

$\underline{0 \text { Stories/short stories.pdf }}$

An example of teaching material for Poems and Songs

https://www.edb.gov.hk/attachment/en/curriculum-development/kla/eng-edu/poems $\%$

20and\%20songs/PDF/poems $\% 20$ and $\% 20$ songs.pdf 